\title{
A pedagogia da alternância na França: de uma discreta experiência a institucionalização na educação profissional
}

The work-linked training in France: from a understated experience to institutionalisation in professional education

Luciane Teixeira da Silva

Resumo: O artigo trata da Pedagogia da Alternância desenvolvida na França. Por meio de revisão bibliográfica foi possível identificar três momentos da Alternância neste país. A primeira experiencia com a Alternância, de caráter popular, baseada na organização dos movimentos sociais e da Igreja Católica; o início do processo de institucionalização e por fim desde os anos 80 até momento atual quando a alternância é identificada como uma via pedagógica primordial para o ingresso no mercado de trabalho. A Alternância é um conceito em processo de evolução e atualmente se constitui como o caminho de excelência para a Educação Profissional na França.

Palavras Chaves: Pedagogia da Alternância, Educação Profissional.

Abstract: The article concerns about the work-linked training developed in France. Through a bibliographical review it was possible to identify three moments of it in this country. The first experience with work-linked training is from a popular character, based on the organization of social movements and the Catholic Church; the beginning of the process of institutionalization and finally from the 80's until today where work-linked training is identified as a primary pedagogical way to enter the employment market. Work-linked training is a concept in the process of evolution and currently constitutes the path of excellence for Professional Education in France.

Keywords: Work-linked training, Professional Education

\section{Introdução}

Este trabalho tem o objetivo de apresentar como a Pedagogia da Alternância vem sendo utilizada atualmente na França e se constituindo como um caminho de excelência para a Educação Profissional. Para compreender o atual estatuto da Alternância, a primeira parte do texto apresenta dois momentos desta pedagogia, o primeiro quando de seu surgimento, e o segundo, quando o processo de mobilizações e reivindicações que resultaram no cooptação da Alternância pelo Estado francês.

O terceiro momento é o atual, no qual a Alternância é identificada como uma via pedagógica de excelência para a entrada no mercado de trabalho, marcada por uma forte institucionalização e regulação do Estado.

Para a produção do texto foi realizada uma revisão bibliográfica sobre a Pedagogia da Alternância na França. Como explica Fonseca (2002), o texto foi 
produzido por meio do levantamento de referências já analisadas e que foram publicadas em formatos de artigos, livros e outros trabalhos científicos. Desse modo, foram privilegiadas fontes de autores franceses, estudiosos da Alternância e também de autores brasileiros que se dedicam ao tema.

Essa tarefa foi possível por conta do Projeto de Cooperação Internacional entre a Universidade Federal do Pará e Universidade Rabelais de Tours e do engajamento de pesquisadores e estudantes dos dois países. Neste projeto é discutida a Pedagogia da Alternância e a Educação Profissional nos dois países identificando similaridades e diferenças.

\section{A primeira experiência: intuição e saber prático}

A Pedagogia da Alternância é um fato educativo surgido no ano de 1935, no espaço rural francês, na comuna de Sérignac-Péboudou, a partir da criação do que se tornaria futuramente a primeira Maison Familiale Rurale - MFR. É uma experiência original que toma como base uma ideia simples, mas com força e valor germinal, que pode ser considerada a responsável pela sua continuidade: o direito a uma educação capaz de melhorar a vida das pessoas que vivem no campo.

A primeira escola não foi planejada por pedagogos ou especialistas em educação, mas pelas próprias famílias dos alunos, que eram agricultores, por membros de sindicatos rurais e da Igreja Católica. Essa primeira experiência foi guiada pela espontaneidade e pela necessidade. Considerada o berço desta ideia (Granereau 1968), a primeira Escola foi organizada para ofertar uma formação técnico-agrícola que tinha como base apenas os cursos por correspondência que Abbe Granerau ${ }^{1}$ teve acesso.

Para que estas ideias e projetos pudessem ser organizados e colocados em prática foi necessária organização, mobilização e diversos encontros onde os participantes discutiam e lapidavam os objetivos para a futura escola, assim sintetizados por Chartier (1978): a) formar uma elite capaz de restaurar a vida no

\footnotetext{
1 Abbé Pierre-Joseph Granereau ou Abbé Granereau foi um sacerdote francês, militante do sindicalismo camponês e um dos fundadores da primeira Casa Famíliar Rural. Ele narra essa experiência no Livro de Lauzun, que é como um diário, escrito aos poucos, com relatos, projetos e cartas trocadas sobre a criação da escola, os primeiros anos e a expansão.
} 
campo; b) restabelecer o valor do trabalho com a terra; e c) suscitar as vocações dos agricultores no ambiente rural e em uma escola adaptada. Essas pessoas, que trabalhavam no campo, no cultivo da ameixa e do figo, queriam que seus filhos tivessem direito à uma educação que não negasse as suas origens camponesas e que fosse capaz de melhorar a vida no campo.

É neste quadro de mobilização e reflexões de um grupo de agricultores que surgiu a proposição de que os jovens, trabalhando nas propriedades de seus pais poderiam se reagrupar periodicamente para adquirir um complemento de formação que fosse adaptado à sua situação de agricultor[...] houve um acordo de que este período de formação complementar seria realizado sob a forma de internato, onde os alunos passariam três semanas em aprendizado prático nas suas propriedades e uma semana em formação teórica na escola. [...] Nascia, assim, aquele que viria a ser uma das características e base fundamental do projeto pedagógico das Maisons Familiales Rurales (MFRs): a alternância entre o trabalho prático na propriedade agrícola e a formação geral técnica no centro de formação. (SILVA, 2012, p. 36 e 37).

O ensino e a alternância eram baseados em três aspectos diferentes e complementares: a formação técnica e teórica, a formação geral e a formação humana e cristã. (CHARTIER, 1978). A formação técnica, ficou a cargo da família, da figura paterna. Os estudos teóricos ficaram sob a direção de um professor designado; a formação geral era variada e tinha o objetivo de ajudar os jovens a se situar no espaço e no tempo, possuía as seguintes disciplinas: história da profissão agrícola, geografia agrícola da França e do mundo, ciências para uma formação agrícola, história natural agrícola e noções de organização de uma secretária, presidência e tesouraria agrícola. E, por fim, a formação humana e cristã, que se deve não apenas ao Padre Granereau, que acreditava que um líder, um militante, não nasce sem um sólido conhecimento sobre os planos humanos e cristãos, e que uma formação cristã proporcionaria uma sólida e rigorosa formação intelectual, disciplinar e moral (CHARTIER, 1978, p. 58 e $59)$.

Aos poucos a experiência foi sendo aperfeiçoada, expandindo-se e sendo replicada em outros lugares e também foi sistematizada por técnicos em pedagogia (Nosella, 2013). De acordo com Silva (2012), em 1942, existiam 17 Escolas que trabalhavam com a Alternância na França com um total de 500 
estudantes. Foi necessário criar coordenações e institucionalizar essa prática. Em setembro de 1942 foi criada a União Nacional das Casas Familiares Rurais.

Ao longo do século $X X$ a Alternância foi aplicada em outros lugares da Europa, como na Itália, e também em países africanos, como o Senegal, chegando até na América Latina, em países como o México, a Argentina e o Brasil. Por aqui as primeiras escolas surgiram no Estado do Espírito Santo, em 1969, por meio da ação de padres italianos da Companhia de Jesus vindos da cidade de Padova, Itália. Segundo levantamento realizado por Nosella (2013), entre o final da década de 90 e início dos anos 2000, as escolas da Pedagogia da Alternância funcionam em 21 dos 27 estados brasileiros.

\section{O início da transição da experiência popular para a institucionalização}

De acordo com Gimonet (1984) "foi necessário, para que ele tivesse (o termo de alternância) o direito de reconhecimento, um longo e laborioso caminho marcado por numerosas experiências, movimentos, informações, colóquios, escritos e textos legislativos" (Gimonet, 1984, p. 41). Apesar do emprego da palavra alternância pelas "Maison Familiales Rurales", o seu uso e disseminação no vocabulário das Ciências da Educação e também na Legislação Educacional francesa vai ocorrer após importantes eventos promovidos pela União Nacional de Casas Famílias Rurais (Union Nationale des Maisons Familiales Rurales) e de seus parceiros, como o Colóquio de Amiens com o tema "Uma outra escola" (une outre école), realizado em março de 1968, e o Colóquio de Rennes, em 1973, intitulado "Ensino Superior em Alternância" (Bachelard, 1994).

Passa-se da compreensão de Alternância que era, até então, praticada no interior das Casas para um conceito aberto, passando a ser discutido de forma ampla por outros pontos de vistas e em meio a um contexto de renovação da política e da educação. Gimonet pontua o colóquio de Rennes como o responsável por causar a "euforia da alternância" em diversos setores do sistema nacional. $\mathrm{O}$ autor destaca que problemas enfrentados pelos jovens como o desemprego e pelo próprio sistema educacional foram os principais responsáveis para que a alternância conquistasse o seu reconhecimento legal. 
Contudo, a travessia da Alternância entre um experiência bem sucedida em uma comunidade no interior francês, nos anos 30 , para um pedagogia que se torna o caminho de excelência para a formação no momento atual, também deve ser creditada ao que Guillaumin (2017), Breton (2018) e Joubert (2012) chamam de escolarização da vida profissional, um processo antigo na França e que pode ser entendido como, a transferência da formação profissional para o espaço escolar, não deixando-a apenas no espaço do trabalho.

Os autores chegam a essa conclusão analisando a legislação francesa e sua própria história da educação. Pode-se concluir, então, que junto com as mobilizações pelo reconhecimento da alternância e as reivindicações em torno de uma escola mais ativa e ligada a realidade, há uma ação estatal de apropriação dessas reivindicações por meio da introdução da Alternância do sistema escolar.

Em princípio as pessoas aprendiam determinada profissão de uma maneira informal, observando quem sabia mais, quem desenvolvia determinada atividade melhor, por meio da troca de experiências, saber ler ou escrever não era uma competência indispensável nesse contexto (Geay, 2016). A industrialização transforma isso de forma muito radical.

De acordo com Brucy and Troger (apud Guillaumin, 2017) o modelo escolar dominou a formação profissional por muito tempo e teve seu início em 1880 com a lei que deu origem ao Ensino Técnico. Em 1919 foi instituído o Certificado de Competência Profissional que fundamenta a formação profissional, cria critérios de estandardização de qualificação e ainda é identificado como um agente da formação profissional. Cada vez mais essas leis vão colocando a cargo da escola (chamados de centros de formação ou centros de aprendizagem) o papel de formar para determinadas profissões. Em algumas áreas surgiram iniciativas de se fundar escolas de negócios, com formações especificas como na área do comércio, que incentivavam o período de estágio na empresa, mas foram iniciativas tímidas e localizadas que não se sustentaram.

Após o final da Segunda Guerra (nos trinta gloriosos 1945-75) a evolução tecnológica provoca novas mudanças na formação profissional e os Centros de Aprendizagem se tornam "Lycées" profissionais. Em 1959 há a criação de 
escolas exclusivas para a formação de técnicos. Com Brucy and Troger (apud Guillaumin, 2017) indica o aumento continuo das matrículas no ensino profissional no período. O ensino e a formação técnica ou profissional ${ }^{2}$ aconteciam em estabelecimentos de ensino sem contato com a empresa. "Há exceções, [...] o treinamento médico, paramédico, social e de engenharia: os períodos no local de trabalho são integrados ao treinamento, mas não são objeto de atenção pedagógica especial". (Idem)

Ou seja, até então, mesmo em áreas em que a formação ocorria por meio da conjugação de espaços distintos, ainda não existia a utilização da palavra alternância. As mudanças que começam a indicar a institucionalização da Alternância ocorrem a partir dos anos de 1980, quando, segundo Guillaumin (2020 apud Pair, c, 2003), há um aumento na duração da formação, mas o nível do treinamento é baixo, assim como o número de jovens empregados. Em 1971 já havia sido promulgada a lei de reforma da formação profissional, conhecida como Lei Delors, que abriu caminho para as mudanças atuais.

Esta lei enquadra a formação profissional como educação permanente e passa a reconhecer a aprendizagem com resultado do período de treinamento prático e dos estudos. A lei também introduz sequencias educativas nas empresas, a partir de 1979, nos cursos ofertados no Liceus profissionais, e cria o "Baccalauréat" profissional, que passou a exigir para obtenção do diploma um período de estágio de 12 a 24 semanas na empresa. A palavra alternância ainda não é utilizada, ele aparece anos mais tarde

desde $1992^{3}$, a palavra "alternância" sob o status da escolarização é claramente mencionada nos textos oficiais que organizavam todos os cursos de treinamento preparatórios para diplomas técnicos e profissionais, em escolas de ensino médio profissionalizante e tecnológico (Guillaumin, 2020, p. 4).

\footnotetext{
2 "L'enseignement et la formation technique ou professionnelle se déroulent dans les établissements scolaires sans contact avec l'entreprise. II y a cependant des exceptions, l'apprentissage tel que défini plus haut, mais aussi les formations médicales, paramédicales, sociales, celles des ingénieurs: les périodes en milieu professionnel sont intégrées dans la formation mais ne font pas l'objet d'une attention pédagogique particulière. " (Guillaumin, 2020 $\mathrm{p}, 4)$

3 "Dès 1992, le mot alternance sous statut scolaire est clairement énoncé dans les textes officiels organisant toutes les formations préparant au CAP, BEP, Bac Pro, BTS etc. dans les lycées professionnels et technologiques
} 
Os pontos destacados revelam um percurso de análise possível sobre a ascensão da alternância, eles foram escolhidos por que explicam esse processo de travessia. A escolarização da vida profissional promoveu um controle tão forte sobre a oferta de educação profissional que acabou ficando fechado dentro da própria escola e a Alternância surge como uma possibilidade de integrar esses dois campos, até então opostos, por exemplo, segundo Guillaumin (2020), as alterações na legislação educacional "abriram" ${ }^{4}$ as escolas às realidades da vida profissional, tendo como objetivo a progressão dos conhecimentos e saber fazer dos alunos" (GUILLAUMIN, 2020 p, 80). Assim, a Alternância na França tenta superar a separação entre o trabalho e a escola. Geay (2016) argumenta que a alternância se torna necessária dada a insuficiência dos estágios, sendo necessário inventar novas mediações didáticas, além da complexificação das formações, havia um conflito entre o que era ensinado na escola de formação e o que era realizado no trabalho. $\mathrm{O}$ desafio posto, era encontrar o alinhamento correto.

\section{A Alternância como estratégia de formação na França - 0 caminho por excelência}

É importante explicar que na França a formação profissional articula a formação inicial para a entrada no mercado de trabalho e a formação continuada, destinada às pessoas que possuem uma profissão e estão desempregadas, que desejam aprofundar os seus conhecimentos no que já sabem fazer ou mesmo aprender uma nova profissão. A distinção entre a formação inicial e continuada depende do momento em que ela acontece na carreira da pessoa. (Guillaumin, 2020).

$\mathrm{Na}$ legislação em vigor existem 4 vias de acesso às formações profissionais e as certificações: formação inicial, sob o regimento escolar ou regimento de aprendizagem (estágio), formação continuada e validação de experiência adquirida. Nesse texto vamos tratar da formação inicial e continuada sob o regimento escolar, destacando dois dispositivos utilizados para colocar em

\footnotetext{
4 "ouvrir l'école aux réalités de la vie active et ont pour objet, la progression des connaissances et des savoir-faire des élèves"
} 
prática a alternância entre o Centro de Formação e a Empresa, o Contrato de Aprendizagem e o Contrato de Profissionalização.

A Alternância é atualmente o caminho de excelência para a formação profissional Inicial e Continuada na França. Dos três itinerários possíveis no Ensino Secundário (Lycée), a Alternância é ofertada em dois deles, o Tecnológico e o Profissional. Ela é considerada o caminho mais eficiente para garantir a entrada dos jovens no mercado de trabalho com formação qualificada, sendo aconselhada pelo governo e pelos estudiosos (Breton, 2018) e (Guillaumin, 2020). Além disso, a Alternância permite também o acesso a formação continuada para jovens e adultos reingressarem ao mercado de trabalho de forma mais qualificados na profissão que já exercem ou mesmo em uma nova, estendendo assim a formação ao longo da vida.

Esses fatores permitem pensar a alternância como um conceito em movimento que sofre diversas alterações, mas que segue em busca de um equilíbrio perdido, no caso Francês, entre a escola e o mundo do trabalho.

Em relação ao percurso profissional escolarizado é importante destacar primeiramente como e quando a alternância se insere na escolarização francesa, desse modo, o objetivo aqui é mostrar o percurso escolar e, ao longo do texto, ir destacando os pontos relevantes para a discussão sobre a Alternância e a educação profissional. No final do tópico faço algumas reflexões sobre as dimensões pedagógicas e epistemológicas que a alternância praticada França levanta.

\section{O percurso profissional escolarizado}

A lei por uma Escola da Confiança (Loi pour une école de la confiance) entrou em vigor em julho de 2019 e seus desdobramentos deverão seguir até o final de 2021. A lei ampliou a educação escolar obrigatória, começando agora aos 3 anos de idade para crianças francesas e estrangeiras e prolongou dos 16 para os 18 anos os anos finais da escola. O objetivo dessa alteração é combater à pobreza e promover o emprego e a inclusão social (Guillaumin, 2020).

O sistema educacional na França está estruturado da seguinte forma. A primeira etapa da educação é a école maternelle (maternal ou educação infantil) 
com entrada aos 3 anos de idade. Em segunda etapa é a école elémentaitre (ou a primeira etapa do ensino fundamental), que recebe crianças dos 6 aos 11 anos, com 5 anos de duração.

O nível seguinte é o collége (equivalente a segunda etapa do ensino fundamental), que possui 4 níveis e tem 4 anos de duração, nesse momento se encontra o final do chamado ciclo de consolidação e o início do ciclo de aprofundamento, isso significa que escola precisa começar a desenvolver nos estudantes competências nas diferentes disciplinas e também no trabalho com a interdisciplinaridade. Além disso, os alunos começam a ser orientados sobre os projetos em relação ao futuro, chamado de "parcours avenir", em tradução livre "percurso futuro". (FRANÇA, 2020).

No final da última etapa do collége, na série chamada troisiéme (terceira), os alunos recebem um diploma (diplôme national du brevet) que os permite avançar nos estudos em direção ao Ensino Secundário, nos Lycées, que constituem a última etapa da educação francesa composta por três séries seconde, prémiere e terminale (segunda, primeira e final). Neste momento, ainda no Collége, quando o jovem tem entre 15 e 16 anos, ele deverá escolher o tipo de escola secundária (Lycée) que deseja ingressar. A opção escolhida será o itinerário que este jovem vai percorrer até realizar o exame Baccalauréat, ao final da última etapa. Este exame permite o ingresso ao ensino superior.

São três opções de Escola Secundária: Lycée Général, Technologique ou Professionnel (Secundário geral e tecnológico ou profissional). Há também os Centros de Formação que ofertam formação geralmente na via profissional. Nas opções Geral e Tecnológico o primeiro ano é comum aos estudantes, as duas últimas séries são organizadas em função da realização do Exame Baccalauréat. A via Geral visa o ingresso em Universidades ou escolas especializadas, enquanto a via tecnológica permite o acesso a oito opções de aprofundamentos em áreas de tecnologia, ambos possuem três anos de duração.

Por sua vez o Ensino Secundário Profissional (Lycée professionnel), realizado por meio da Alternância, é voltado para o ingresso no mercado de trabalho, aquisição de experiência profissional, de emprego e salário. Nesta opção entre $40 \%$ a $60 \%$ do tempo do aluno é voltado para o aprendizado na 
prática e de tecnologias (França, 2020). As aulas acontecem geralmente fora da escola de acordo com a especialidade escolhida, em empresas, laboratórios, etc. As matérias de ensino geral também são ministradas, mas com uma carga horaria menor. São três anos de duração, o mesmo dos outros, a diferença é que são 3 anos na mesma via, além disso apenas a profissional pode ser realizada em Alternância.

Outra via proposta ao finalizar o collége é a entrada direta no mercado de trabalho por meio da obtenção do Certificat d'Aptitude Professionnelle (CAP) ou certificado de competência profissional, obtido após a realização de curso com duração de dois anos. Esta opção oferece uma formação mais rápida e focada em uma profissão.

São mais de 200 opões de especializações profissionais que Escolas Secundárias Profissionais e Centros de Formações podem ofertar e certificar. As opções de especialização devem estar registradas no Diretório Nacional de Certificações Profissionais, que reúne todas as titulações profissionais regulamentadas pelo Ministério do Trabalho francês. Os diplomas são todos controlados pelo Estado, que certifica e controla os critérios de qualificação, eles possuem validade nacional e também os seus equivalentes na União Europeia.

Também há a possibilidade de o aluno obter o Brevet d'Études Professionnelles, que é um diploma de formação técnica secundária, o curso é realizado em 3 anos em uma Escola Secundária Profissional (Lycée professionnel) por fim, ainda existem os "lycées des métiers" ou escola de profissões. Todas essas escolas reúnem a oferta de uma formação profissional inicial ou formação continuada, o que elas têm em comum é a sua organização, que acontece por meio da Alternância.

Cabe destacar que os percursos escolhidos não são irreversíveis, ao aluno é facilitado as trocas entre as vias geral, tecnológica ou profissional. A orientação sobre a escolha do percurso é feita com base no histórico escolar do aluno e ainda nas suas aptidões pessoais e familiares. Além disso, a escolha pela via profissional não elimina a possibilidade de continuidade dos estudos em uma Universidade. A escola secundária profissional prepara para o jovem para 
prestar o exame de Baccalauréat e obter um Brevet de Technicien Supérieur $B T S$, que é um curso técnico superior.

Também podem usufruir desse processo de qualificação os adultos que abandonaram os estudos ou que já possuem uma profissão e querem se qualificar ou requalificar, por isso a formação pode acontecer tanto em uma Escola Secundária Profissional ou no Centro de Formação.

Seja como um aluno do secundário profissional, da educação continuada ou até mesmo como universitário a formação desse jovem ou adulto na formação profissional acontece por meio da Alternância realizada entre dois espaços: A escola/centro de formação e uma empresa. A relação entre eles é realizada por meio de dois tipos de contratos: o contrato de aprendizagem e pelo contrato de profissionalização.

\section{Contrato de aprendizagem}

Está forma de contrato é voltada para jovens entre 16 e 29 anos e, em algumas situações, para pessoas com mais de 30 anos. Também para portadoras de necessidades especiais. Jovens com menos de 15 anos podem se submeter a este contrato, no entanto eles precisam ter concluído o nível do Collége.

Os locais e as áreas em que esse jovem poderá trabalhar se diversificam de acordo com a oferta da sua região. De qualquer forma eles variam entre trabalhos voltados para a alimentação, comércio, construção civil e obras públicas, negócios, hotelaria, serviços de higiene pessoal, setor automotivo e eletrônica.

O jovem em alternância possui o status de funcionário dentro da empresa e o tempo de alternância é remunerado, ou seja, o período no centro de formação é considerado trabalho, assim como na empresa. No centro de formação ele deverá seguir as disciplinas propostas e realizar os exames previstos. Na empresa o jovem está sob a responsabilidade de um mestre, pessoa designada como o seu responsável no local, geralmente um funcionário que tem mais conhecimentos e experiências na área que o jovem deseja se especializar. 
O tempo de formação é de pelo menos $400 \mathrm{~h}$ por ano. $800 \mathrm{~h}$ garantem o Certificado de Aptidão Profissional, que tem duração de 2 anos e são ministrados em Centros de Formação. Esse tempo de duração é menor do que o ministrado nas Escolas Secundárias profissionais e ou nas escolas de tecnologias.

Neste modelo de contrato o período em Alternância varia conforme o nível, primeiro, segundo ou terceiro ano, e o diploma pretendido. A alternância pode ser de 2 dias no centro de formação e 3 dias na empresa; 1 semana no centro de formação e 3 semanas na empresa. 2 semanas e 1 mês no centro de formação e o mesmo tempo na empresa (France, 2020). Dependendo da especialidade escolhida, o primeiro ano pode ser exclusivo de disciplinas teóricas e os dois últimos anos apenas na empresa.

O tempo de alternância semanal, tempo dispensado para a formação na empresa e/ou no centro de formação é de 35 horas. Se o aluno for maior de idade, 18 anos ou mais, esse tempo aumenta para até 48 por semanas, o tempo é estendido em função do trabalho na empresa e não da formação. Além disso, o jovem em alternância possui os mesmos direitos que um trabalhador regular, como descanso remunerado, licença maternidade, seguro por acidente de trabalho, etc.

Durante o seu período na empresa o jovem ficará sob os cuidados do mestre, que também será o responsável por fazer a integração entre as atividades desenvolvidas na empresa e o centro de formação, informando sobre o desenvolvimento do aluno e o seu desempenho, registrando essas informações no Livro de aprendizagem do aluno, por onde ele é avaliado.

Por meio deste contrato o jovem recebe um salário que é calculado a partir do salário mínimo e varia de acordo com a sua idade e com o período de sua formação, variando entre $27 \%$ do salário mínimo para jovens entre 16 e 17 anos no primeiro ano e até $100 \%$ do salário mínimo para jovens de 26 anos no terceiro ano.

A escolha sobre o local, a empresa onde a alternância vai ser realizada, fica a cargo do jovem. A escolha é geralmente orientada pelo centro de formação ou pela Escola Secundária, que já possui a sua lista de empresas com os 
trabalhos disponíveis. Empresas públicas, privadas e associações podem ser parceiras para a formação em alternância.

\section{O contrato de profissionalização}

O contrato de profissionalização é outro dispositivo utilizado para instituir a formação profissional em alternância. Destina-se a pessoas entre 16 e 26 anos que buscam um emprego, pessoas com deficiência, titulares de algum benefício social e outras que queiram reingressar no mercado de trabalho ou que queiram descobrir uma nova formação, ou seja, ele é voltado prioritariamente para uma formação continuada. As horas e formas de organização dispensadas entre o Centro de Formação e a empresa são parecidas com o Contrato de Aprendizagem e variam de acordo com a formação pretendida, mas a sua duração é menor, além disso, empresas públicas não participam deste tipo de contrato. A figura que acompanha o jovem-trabalhador é a de um tutor que vai guia-lo dentro da empresa.

Segundo dados do governo francês (2020) 7 meses após finalizar o estágio em alternância o jovem já está empregado. $59 \%$ dos que possuem o certificado de aptidão profissional possuem emprego, a porcentagem aumenta para $68 \%$ para os alunos que terminaram os estudos em uma Escola Secundaria Profissional (Lycée) e $80 \%$ para os que possuem o Curso Técnico Superior (BTS). Além disso, cerca de $40 \%$ dos jovens reingressam na empresa que realizaram a alternância após a formatura.

\section{Conclusão}

O objetivo principal desse artigo era o de sistematizar a forma como a Alternância é utilizada atualmente na França na formação profissional, levando em consideração que foi neste espaço que ela surgiu por meio do Movimento das Maisons Familiales Rurales. Por conta dessa sistematização foi possível identificar que a Alternância passou por três momentos desde a sua primeira experiência na Comuna de Sérignac-Péboudou. 
No berço da sua criação a Alternância surge da intuição e do saber prático, uma forma da educação popular, do povo, dos movimentos sociais e da Igreja. Deste processo é criada e fundada a primeira escola, ainda que de forma experimental, consegue garantir resultados positivos, que podem ser constatados pela sua continuidade e pela força da sua ideia geradora: formar líderes rurais, pessoas capazes de trabalhar e estudar no meio rural, mantendoo sempre vivo.

O segundo momento se inicia quando a Alternância começa a aparecer como uma possibilidade pedagógica para além do espaço rural, em virtude de reivindicações por uma escola que atendesse novas necessidades e também pela a atuação do movimento das Maisons Famililaes e sua capacidade de mobilização. Ela começa a despontar na educação profissional, algumas escolas passam a adotar a Alternância e ela começa a aparecer ainda de forma tímida na legislação.

O terceiro momento se inicia desde os anos 80 até os dias atuais, quando a Alternância é identificada como uma via pedagógica de excelência para a formação profissional, passando a caracterizar um forte vínculo com o emprego e o mercado de trabalho. Nesse contexto encontra-se uma legislação consolidada com escolas e instituições próprias para este fim. A marca desse momento é a Alternância como um caminho que leva até o emprego. Além disso ela perde o seu caráter popular e se torna mais burocratizada, com a mediação marcada pelos contratos de aprendizagem e de profissionalização, bem como, uma forte presença do Estado, que controla as ofertas de cursos e certificações.

Como indicado pelo texto a Alternância trouxe em sua origem o objetivo principal de formar líderes rurais, pessoas que conhecem e gostam da vida e do trabalho no campo e com a formação necessária seriam capazes de melhorar a vida nesse espaço. Desse modo, é possível afirmar que mesmo após todas essas transformações, este objetivo permanece conservado, mas de uma forma modificada? em outras palavras, a Alternância ainda busca formar líderes?

Nesse sentido, ser líder é ter uma formação, um emprego, ter autonomia ou estar inserido em uma atividade produtiva. Não cabe julgar qual desses 
objetivos é o melhor, mas indicar os resultados dessas transformações e do processo de institucionalização da alternância.

A partir da análise documental realizada na literatura sobre a educação profissional na França foi possível inferir que os autores afirmam que ao jovem é dada a opção de escolher um caminho profissional baseado em seu percurso escolar. Contudo, essas escolhas estão condicionadas a diversos fatores econômicos e sociais, por exemplo, a escolha entre os estudos gerais ou tecnológicos, que levam até universidades ou escolas especializadas, ou uma entrada direta no mercado de trabalho é permeada por estes fatores.

Não podemos esquecer que essas escolhas são tomadas baseadas principalmente na realidade desses jovens. Em um contexto onde a entrada no mercado de trabalho cada vez mais precoce é demanda, aos 15 ou 16 anos, o jovem de fato escolhe um caminho pensando em seu futuro ou no seu presente, na sua realidade imediata? Cabe ainda questionar se ele tem condições de fazer essa escolha.

No artigo não há condições de se discutir a realidade da juventude francesa, embora isso deva ser levado em consideração quando falamos de escolhas profissionais na juventude. Sobre a indefinição profissional, fica claro que no contexto francês a alternância não valoriza a incerteza e a insegurança do jovem acerca do futuro profissional, ao contrário o percurso precisa ser definido desde cedo.

Guiullamin (2017) defende a Alternância como um conceito em movimento, ainda em transformação, assim devemos ficar atentos aos contornos que a Alternância deverá desenvolver e também da resposta dos alunos e do mercado de trabalho a esse modelo. Para Jobert (2012) a Alternância pode ser resumida como um fato social, complexo, embaralhado de dimensões sociológicas, políticas, econômicas, epistemológicas, pedagógicas e pessoais. Problematizar a Alternância é revelar a sua atualidade, e estar certo de que teremos muitos questionamentos para responder dada essa característica de vitalidade e do seu movimento.

É por meio da narrativa do combate ao desemprego e da empregabilidade que a Alternância alcança o seu atual status de caminho de excelência para a 
formação profissional e para emprego. O objetivo principal é estreitar as relações entre a formação e a empresa, provendo o ingresso no mercado de trabalho. Nesse contexto, de acordo com Guiullamin (2020),

A Alternância deixa de ser um impensado teórico e se torna a ligação entre a escola ou, mais geralmente, o treinamento e a empresa como um local de prática profissional e aprendizagem, tanto no treinamento inicial quanto no contínuo. É uma forma de organizar a relação entre conhecimento e ação. (GUIULLAMIN 2020, p.75 grifo meu)

O impensado teórico o qual a autora se refere é a experiencia espontânea, carregada de intuição, como foi caracterizada a primeira escola. Como foi exposto no trabalho, nem sempre foi assim. Foi a partir dos anos 1980 que aumentou a atenção oficial para a Alternância a partir de uma crença de que ela fosse possuidora de uma capacidade de motivar os adolescentes em relação a vida profissional (Bachelard, 1994).

Gimonet (1984) destaca fatores de ruptura da Alternância, ao permitir a articulação de dois setores distintos e da sociedade, a empresa, o local de trabalho e a escola. O mesmo autor ainda destaca que é necessário cautela ao identificar a alternância como uma renovação educativa, capaz de superar rupturas, pois ela tem limites e algumas confusões em relação a prática.

Outro ponto de reflexão, levantado no texto é sobre a formação e a participação dos professores, quem são os responsáveis pela condução do ensino, o Centro de Formação ou os mestres nas empresas? As pessoas que trabalham na empresa recebem algum tipo de formação pedagógica específica ou estão cumprindo uma função em seu emprego, eles devem respostas aos seus superiores ou ao Centro de Formação?

Nesse sentido, cabe ainda questionar, qual o equilíbrio que existe entre essas duas instituições, pois o aluno pode ser atraído a se dedicar mais às atividades no local de trabalho, visando a efetivação no emprego, enquanto o período na escola pode se tornar apenas uma formalidade. De que forma essa alternância, não se torna apenas o revezamento entre dois espaços distintos e garante o seu caráter formativo e integrador? 


\section{Referências}

BACHELARD, P. Aprendizagem e práticas da Alternância. Paris: L'Harmattan, 1994.

BRETON, H. (2018). La Reconnaissance et la Validation des acquis de l'expérience en France: le paradigme de l'expérientiel à l'épreuve des certifications. In Formazione Continua e Educazione degli Adulti: le dimensioni formale, non formale e informale nel confronto fra Italia e Francia. VOL 13, N. ALL 30, 1 - 100, p. 62-72.

CHARTIER, Daniel. Naissance d'une Pedagogie de L'alternance. UNMFREO, 1978

GEAY, André. L'alternance comme processus de professionnalisation: implications didactiques In: La professionnalisation en formato: Textes fondamentaux [en ligne]. Mont-Saint-Aignan: Presses universitaires de Rouen et du Havre, 2016 (généré le 14 août 2020). Disponivel em: <http://books.openedition.org/purh/1516>

GUILLAUMIN, C. 2017. La formation en alternance en France. In Formazione Continua e Educazione degli Adulti: le dimensioni formale, non formale e informale nel confronto fra Italia e Francia. VOL 13, N. ALL 30, 1 - 100. 75-87

GUILLAUMIN, C. 2019. La pedagogie de l'alternance en tant que strategie de formation professionnelle en france etat des lieux et questionnements. Revista $\begin{array}{lllll}\text { Humanidades. } & \text { V.7. } & \text { N12 } & \text { (2020). } & \text { Disponivel }\end{array}$ <https://revista.unitins.br/index.php/humanidadeseinovacao/article/view/3078>

GRANEREAU, Abbé. Le Livre de Lauzun: Une histoire de premières Maison familiales rurales Primeira Edição: Comité d'Action "École et Vie Rurale", 1968 Paris: L'Harmattan, 2007

Jobert, G.1991. La place de l'expérience dans les entreprises. In La formation expérientielle des adultes. La Documentation Française. Pp. 75-82. Recherche En Formation Continue. Paris.

FRANCE. Ministère de L'éducation Nationale, de la Jeunesse et des Sports. Le Collége. Disponível em <https://www.education.gouv.fr/le-college-4940> Acesso em 21 de julho de 2020.

FRANCE. Ministère de L'éducation Nationale, de la Jeunesse et des Sports. Le Lycée. Disponível em <https://www.education.gouv.fr/le-lycee-41642> Acesso em 23 de julho de 2020.

FONSECA, J. J. S. Metodologia da pesquisa científica. Fortaleza: UEC, 2002. Apostila

NOSELLA, Paolo. Educação no campo: origens da pedagogia da alternância no Brasil / Paolo Nosella. Vitória: EDUFES, 2013. 
SILVA, Lourdes Helena. As Experiências de formação de jovens do campo: Alternância ou Alternâncias? Curitiba. Editora CRV, 2012.

GIMONET, Jean-Claude. Alternância e relações humanas. Paris: Messonance: Unmfreo, 1984.

Sobre a autora

\section{Luciane Teixeira da Silva}

luciane.teixeira.silva@gmail.com

Mestre em Educação e Pesquisadora do Grupo de Estudos e Pesquisas a Escola de Gramsci - Ufscar. Bolsista Capes. Lattes: http://lattes.cnpq.br/0495011691036166, ORCID: http://orcid.org/0000-00028967- 6298. 